\title{
STUDI RADIOLISIS AIR RINGAN DAN PENGUKURAN LAJU DOSIS BAHAN BAKAR PADA KOLAM PENYIMPANAN BAHAN BAKAR BEKAS (ISSF)
}

\author{
Cyntia Agustin $^{1}$, M. Romli ${ }^{2}$, Sofia Loren Butarbutar ${ }^{3}$, Rahayu Kusumastuti ${ }^{3}$, Sriyono ${ }^{3}$, Geni \\ Rina Sunaryo ${ }^{3}$ \\ ${ }^{1}$ Universitas Padjadjaran, Jurusan Fisika \\ ${ }^{2}$ Pusat Teknologi Limbah Radioaktif -BATAN \\ ${ }^{3}$ Pusat Teknologi dan Keselamatan Reaktor Nuklir - BATAN \\ Email: cyntiagustin@gmail.com
}

\begin{abstract}
ABSTRAK
STUDI RADIOLISIS AIR RINGAN DAN PENGUKURAN LAJU DOSIS BAHAN BAKAR PADA KOLAM PENYIMPANAN BAHAN BAKAR BEKAS (ISSF). Elemen bahan bakar bekas masih mengandung sejumlah uranium diperkaya dengan paparan radiasi yang sangat tinggi, sehingga digunakan air sebagai media penyimpanan bahan bakar bekas pada kolam ISSF agar paparan radiasi bahan bakar tidak keluar ke lingkungan. Paparan radiasi dalam air dapat menyebabkan adanya pembentukan oksigen yang dapat menyebabkan korosi pada material ISSF. Laju dosis dapat terukur dalam suatu sumber radiasi terhadap besarnya penahan radiasi. Laju dosis ini digunakan sebagai input parameter untuk reaksi radiolisis sehingga konsentrasi pembentukan oksidator dalam air dapat diprediksi. Hubungan antara laju dosis terhadap jarak sumber radiasi (tebal penahan) menjadi penting untuk penerapan proteksi radiasi. Metode untuk mengukur laju dosis pada kolam ISSF dilakukan pada rak bahan bakar bekas serta pada kelongsong bahan bakar bekas. Laju dosis diukur dengan detektor radiagem dengan kabel yang terbungkus plastik. Hasil percobaan menunjukkan bahwa hubungan antara laju dosis radiasi terhadap sumber radiasi yaitu semakin besar jarak detektor terhadap sumber radiasi semakin kecil laju dosis yang terukur dan bersifat eksponensial.
\end{abstract}

Kata kunci: kolam ISSF, radiasi, radiolisis air, laju dosis, detektor

\section{ABSTRACT}

STUDY ON WATER RADIOLYSIS AND FUEL DOSE RATE MEASUREMENT IN THE INTERIM STORAGE FOR SPENT FUEL (ISSF). Spent fuel elements still contain enriched amounts of uranium with very high emission of radiation, so water is used as a storage medium in the ISSF pools to prevent radiation exposure into the environment. Radiation exposure in the water can lead to the formation of oxygen to cause corrosion of ISSF material. The dose rate is used as the parameter input for the radiolysis reaction so that the oxygen concentration in the water can be predicted. The relationship between the dose rate to the radiation source distance (thickness of the shield) becomes important for the application of radiation protection. Method for measuring dose rates in the ISSF pool is conducted on the spent fuel racks and on the spent fuel cladding. The dose rate is measured by a radiation detector with a plastic-covered cable. The experimental data shows that the correlation between radiation dose rate to the radiation source is that the bigger the detector distance to the radiation source the smaller the measured dose having exponential rate.

Keywords: ISSF pool, radiation, water radiolysis, dose rate, detector 


\section{PENDAHULUAN}

Pembangkit listrik tenaga nuklir digunakan bahan bakar Uranium 235 untuk menghasilkan reaksi fisi yang dapat menghasilkan energi termal untuk pembangkit daya. Ketika neutron ditembakan pada atom U235 maka reaksi fisi akan terjadi dan menghasilkan 3 neutron sehingga hasil neutron ini digunakan untuk reaksi fisi pada generasi selanjutnya. Rekasi fisi ini selain menghasilkan neutron juga menghasilkan pancaran radiasi berupa $-\gamma,-\beta,-\alpha$. Setelah bahan bakar U-235 telah habis pakai maka bahan bakar ini akan didinginkan di kolam reaktor baru kemudian disimpan di dalam kolam ISSF (Interim Stroge for Spent Fuel) yang berda di samping $\mathrm{RSG}^{[1]}$. Limbah bahan bakar bekas ini ditempatkan dalam rak penyimpanan material SS304. Elemen bahan bakar bekas masih mengandung sejumlah uranium diperkaya dengan paparan radiasi yang sangat tinggi, sehingga digunakan air sebagai media penyimpanan bahan bakar bekas pada kolam ISSF agar paparan radiasi bahan bakar tidak keluar ke lingkungan. ${ }^{[2]}$

Radiasi pada dasarnya merupakan proses pemindahan energi, dalam radiasi nuklir dipancarkan 3 jenis radiasi yaitu alpha, beta dan gamma. Karena radiasi ini dapat berpengaruh buruk terhadap makhluk hidup sehingga diperlukan adanya proteksi radiasi. Dalam prinsip proteksi radiasi dikenal 3 parameter yakni waktu, jarak dan perisai/penahan. Dalam kolam bahan bakar bekas (ISSF) digunakan media air sebagai penahan radiasi yang bertujuan mengurangi intensitas radiasi dengan memanfaatkan interaksi radiasi dengan materi yaitu dengan mengubah energi radiasi menjadi energi panas sehingga paparan radiasinya menjadi berkurang. Interaksi radiasi dengan materi dipengaruhi oleh jenis materi, energi radiasi dan jenis radiasi.

Laju dosis dapat terukur dalam suatu sumber radiasi terhadap besarnya penahan radiasi. Hubungan antara laju dosis teradap jarak sumber radiasi (tebal penahan) menjadi penting untuk penerapan proteksi radiasi. Selain itu laju dosis dapat digunakan sebagai salah satu parameter input dalam analisis radiolysis air untuk memprediksi adanya korosi air dalam kolam $\operatorname{ISSF}^{[2]}$.

\section{TEORI}

Dosis radiasi adalah jumlah radiasi yang terdapat dalam medan radiasi atau jumlah energi radiasi yang diserap atau diterima oleh materi yang dilaluinya. Besaran dosis radiasi dengan menyatakan jumlah radiasi yang terdapat dalam medan radiasi antara lain paparan, fluks, dan intensitas, sedangkan besaran dosis radiasi dengan menyatakan jumlah energi radiasi yang diterima oleh materi yang dilaluinya adalah dosis serap ${ }^{[3]}$ Dosis serap dinyatakan dalam satuan Gray (Gy). Dalam kolam penyimpanan bahan bakar bekas (ISSF) ini terdapat 3 jenis pancaran radiasi hanya saja yang dapat terukur diasumsikan hanya radiasi gamma karena untuk radiasi alpha dan betta terjadi relative kecil. Karena adanya perbedaan jenis radiasi tersebut sehingga diperlukan adanya besaran dosis yang tidak bergantung pada jenis radiasi. Besaran tersebut adalah Dosis ekivalen yang memiliki satuan Sievert $(\mathrm{Sv})^{[4]}$ Sehingga dalam hal ini laju dosis dapat didefinisikan besarnya dosis radiasi yang diserap oleh suatu materi persatuan waktu dengan satuan Sievert/jam (Sv/h).

Bila harus bekerja pada jarak yang dekat dengan sumber radiasi dan dalam waktu yang lama, perisai dapat mereduksi pemaparan hingga serendah-rendahnya. Keefektifan perisai ditentukan oleh interaksi radiasi dengan atom-atom perisai yang juga tergantung pada macam energi radiasi dan nomor atom materi perisai. Proses pelemahan gamma dalam bahan pelindung bersifat eksponensial. Laju dosis gamma di suatu titik setelah melalui suatu bahan penahan, dapat ditulis sebagai berikut: 
$D_{t}=D_{o} e^{-\mu x}$

$D o=$ laju dosis tanpa penahan,

$\mu=$ koefisien absorbsi linier, yaitu fungsi penahan yang bersangkutan dan energi sumber radiasi, (panjang) ${ }^{-1}$,

$x=$ tebal penahan, (panjang)

HVT (Half Value Thickness) untuk bahan penahan radiasi tertentu adalah tebal bahan yang diperlukan untuk mengurangi intensitas radiasi menjadi setengah dari intensitas sebelum dilemahkan oleh penahan. Dari rumus (1) untuk t $=$ HVT diperoleh:

$D_{t}=1 / 2 . D_{o}$

Sehingga diperoleh harga HVT $=0,693$. Dengan kata lain, rumus di atas dapat ditulis menjadi:

$D_{t}=D_{o} \cdot 2^{-t / H V T}$

Konsep HVT ini sangat berguna untuk menghitung secara cepat tebal bahan penahan yang diperlukan. ${ }^{[5]}$.

Kajian pengaruh radiasi terhadap air telah ada sejak 1940 dan terus berkembang hingga adanya kajian mengenai radiolysis air. Air bila diradiasi akan terdekomposisi melalui 2 proses, yaitu eksitasi dan ionisasi ${ }^{[6-7]}$. Proses irradiasi akan menghasilkan produk hasil dari dekomposisi molekul air yang menghasilkan radikal bebas dan produk molekul $\left(\mathrm{H}_{2}, \mathrm{H}_{2}, \mathrm{O}_{2}\right)$ dan Oksigen $\left(\mathrm{O}_{2}\right)^{[8-9]}$. Bentuk akhir dari produk -produk tersebut disebut sebagai produk primer seperti yang tertulis pada persamaan reaksi dibawah ini:

$$
\mathrm{H}_{2} \mathrm{O} \rightarrow e_{a q}^{-}, \mathrm{H}_{3} \bullet \mathrm{OH}_{3} \mathrm{H}^{+}{ }_{,} \mathrm{H}_{2}, \mathrm{H}_{2} \mathrm{O}_{2}
$$

Proses tersebut berjalan sangat cepat dalam rentang waktu $10^{-8}$ detik. Kemudian produkproduk tersebut akan saling bereaksi satu sama lain atau dengan zat-zat yang terlarut yang akhirnya membentuk suatu senyawa yang stabil $^{[10-11]}$. Oksigen merupakan produk hasil reaksi dari proses radiolisis dan merupakan oksidator yang akan menginisiasi terjadinya korosi dan degradasi pada material. Korosi ini dapat meningkatkan biaya operasi dan perbaikan serta menyebabkan adanya pancaran radiasi yang berbahaya bagi manusia. Dalam hal ini air merupakan faktor yang terpenting dalam mekanisme korosi.

Proses radiolisis di dalam sistim kimia bergantung pada beberapa faktor seperti tipe radiasi, energi radiasi, dosis yang diserap, laju dosis dan komposisi kimia. Produk fisi uranium 235 selain menghasilkan neutron juga menghasilkan pancaran radiasi radiasi berupa $\gamma,-\beta,-\alpha$. Dalam hal tipe radiasi beberapa penelitian dengan menggunakan program facsimile telah dilakukan bagaimana karakterisasi tipe radisi terhadap produk radiolysis yang terbentuk dalam hal ini konsentrasi oksigen sebagai penyebab korosi pada rekator RSGGAS dimana radiasi sinar $-\gamma$ menghasilkan konsentrasi oksigen yang lebih sedikit dibandingkan dengan neutron. Oksigen merupakan produk kedua (bukan produk primer dari radiolisis) namun radikal bebas terbentuk lebih besar oleh sinar gamma dibandingkan dengan neutron. Ini dikarenakan karakteristik dari neutron yang merupakan high LET yang mendeposisikan energinya pada kerapatan yang relative lebih tinggi dibandingkan dengan sinar gamma ${ }^{[6]}$.

\section{TATA KERJA}

Pengukuran laju dosis dilakukan pada rak bahan bakar di kolam ISSF dan uji cicip pada 1 kelongsong bahan bakar bekas. Adapun peralatan yang digunakan dalam mengukur laju dosis ini antara lain:

1. Detektor Radiagem

2. Kabel dengan pembungkus plastic 
3. Rak dan klongsong bahan bakar bekas

Untuk pengukuran laju dosis pada rak bahan bakar bekas, detector radiogem dengan kabel plastic dimasukan ke dalam kolam ISSF hingga detector kontak dengan rak bahan bakar. Lalu kabel diangkat setiap $10 \mathrm{~cm}$ dan diukur nilai laju dosisnya setiap kenaikan $10 \mathrm{~cm}$ hingga $40 \mathrm{~cm}$. Untuk pengukuran laju dosis pada sebuah klongsong bahan bakar bekas, 1 kelongsong bahan bakar bekas digantungkan pada kolam ISSF. Kabel detektor dimasukkan ke dalam kolam ISSF hingga kedalaman $200 \mathrm{~cm}$, lalu kabel diangkat setiap $10 \mathrm{~cm}$ dan diukur nilai laju dosisnya setiap kenaikan $10 \mathrm{~cm}$ hingga permukaan air.

\section{HASIL DAN PEMBAHASAN}

Gambar 1 merupakan grafik hubungan antara laju dosis radiasi terhadap jarak sumber radiasi. Dalam hal ini detektor radiagem diturunkan hingga kontak dengan sebuah rak bahan bakar bekas dalam kolam ISSF. Setelah kontak, detektor menunjukan harga yang overload dari skala maksimal yang terbaca oleh detector yaitu sebesar $9999 \mathrm{~Sv} / \mathrm{h}$. Ketika detektor diangkat $10 \mathrm{~cm}$ dari rak bahan bakar bekas laju dosis yang terukur munurun secara drastis hingga mencapai $5.32 \mathrm{~Sv} / \mathrm{h}$ dan nilai semkain menurun seiring dengan pertambahan jarak antara detector dan rak bahan bakar bekas seperti yang bisa terlihat dalam grafik hubungan antara laju dosis terhadap jarak bahan bakar bekas diatas. Hal ini sesuai dengan hukum kuadrat terbalik dimana ketika sinar gamma dipancarkan ke segala arah intenistas atau laju dosis radiasi di suatu titik akan semakin lemah karena berbading terbalik dengan faktor kuadrat jaraknya dari sumber radiasi. Penurunan signifikan laju dosis terhadap penambahan jarak dari sumber bahan bakar bekas bersifat eksponensial, yang sesuai dengan teori dan perumusan bahwa ketika sinar gamma melewati suatu materi maka akan terjadi penurunan intensitas atau laju dosis secara eksponensial karena radiasi gamma dalam materi akan lepas dari berkas radiasi sejajar setelah bertumbukan dan selanjutnya akan terhambur.

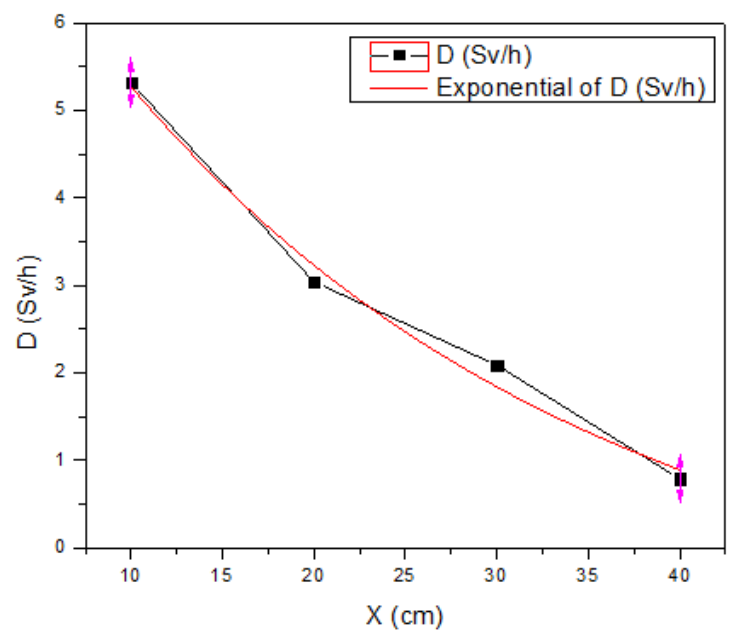

Gambar 1. Grafik Hubungan antara Laju Dosis terhadap Jarak Sumber Radiasi (rak bahan bakar bekas) dalam Kolam Penyimpnan Bahan Bakar Bekas (ISSF)

Walaupun radiasi tidak dalam bentuk berkas radiasi sejajar, dalam bahan penahan yang tipis jumlah hamburan radiasi gamma sangat sedikit, maka hukum eksponensial masih bisa digunakan. Sebaliknya, radiasi yang terhambur dalam materi akan menjadi banyak bila bahan penahan semakin tebal. Maka, intensitas yang dihasilkan akan lebih rendah. Dalam kolam bahan bakar bekas ini digunakan medium air sebagai penahan radiasi dari bakan bakar bekas. Dalam kolam penyimpanan bahan bakar bekas(ISSF) ini sebenernya terdapat 3 jenis pancaran radiasi hanya saja yang dapat terukur diasumsikan hanya radiasi gamma karena untuk radiasi alpha dan betta terjadi relatif kecil. Laju dosis yang terukur juga merupakan kontribusi dari beberapa bahan bakar bekas (tidak hanya 1 rak) yang ada dalam kolam penyimpanana bahan bakar bekas tersebut. 
Gambar 2 menunjukan grafik hubungan antara laju dosis terhadap sebuah klongsong bahan bakar bekas yang digantungkan pada kolam ISSF dan terdapat jarak yang tidak diketahui antara jarak dasar kolam dengan letak bahan bakar bekas tersebut. Detector dimasukan hingga ke kedalaman $200 \mathrm{~cm}$ dari atas permukaan air lalu mulai diamati nilai laju dosisnya setiap kenaikan $10 \mathrm{~cm}$.

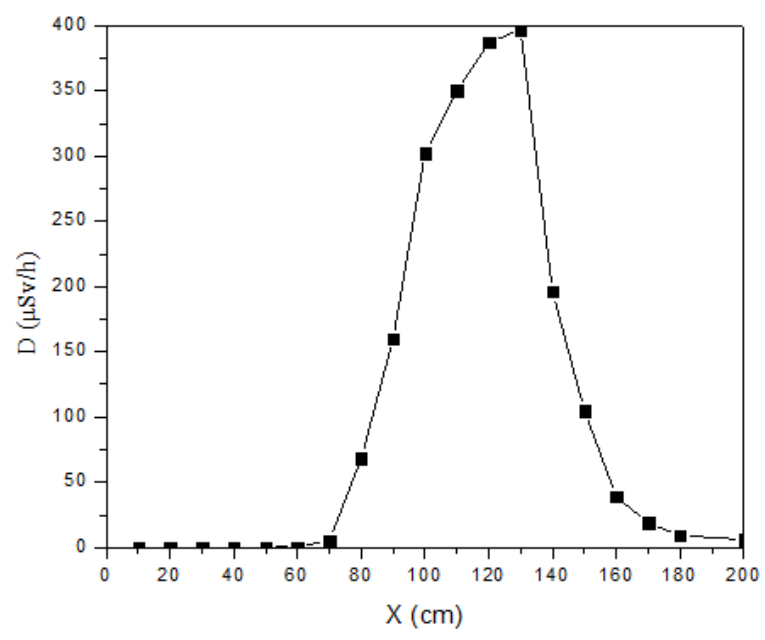

Gambar 2. Grafik Hubungan antara Laju Dosis terhadap Jarak Sumber Radiasi (satu klongsong bahan bakar bekas) dalam Kolam Penyimpnan

Bahan Bakar Bekas (ISSF)

Laju dosis bernilai konstan dari jarak kenaikan $10 \mathrm{~cm}$ hingga $50 \mathrm{~cm}$ yaitu bernilai $0.18 \mathrm{~Sv} / \mathrm{h}$. Dari jarak kenaikan detector $60 \mathrm{~cm}$ hingga 130 cm laju dosis mengalami kenaikan secara signifikan. Ini menandakan jarak detector berada di sepanjang kelongsong bahan bakar bekas sehingga nilai laju dosisya naik secara signifikan pada jarak kenaikan $60 \mathrm{~cm}$ hingga $130 \mathrm{~cm}$ (kedalaman $140 \mathrm{~cm}$ hingga $70 \mathrm{~cm}$ dari atas permukaan air kolam ISSF) tersebut. Dan laju dosis menurun kembali dari kenaikan jarak 140 cm hingga $200 \mathrm{~cm}$ (kedalaman $60 \mathrm{~cm}$ hingga di permukaan air kolam ISSF), yang menandakan jarak detector semakin jauh kembali dari klongsong bahan bakar bekas tersebut. Grafik diatas juga bersifat eksponensial baik ketika grafik tersebut cenderung naik maupun turun dan sesuai dengan teori dimana laju dosis bersifat eksponensial terhadap jarak. Laju dosis yang terukur dari satu klongsong bahan bakar bekas jauh labih kecil dibandingkan dengan pada percobaan pada rak bahan bakar bekas, ini dikarenakan tidak ada kontribusi radiasi dari bahan bakar bekas yang lain dan hanya radiasi dari satu klongsong bahan bakar itulah yang terukur laju dosisnya.

Laju dosis merupakan salah satu parameter input untuk mengetahui pembentukan oksidator dalam air karena adanya fenomena radiolysis. Semakin tinggi laju dosis maka akan semakin banyak jumlah paparan radiasi dalam material (air) sehingga konsentrasi pembentukan oksidator dalam air pun akan semakin meningkat. Oksidator ini dapat menyebabkan korosi pada material yang ada dalam kolam bahan bakar ISSF. Sehingga semakin banyaknya konsentrasi oksidator semakin cepat suatu bahan terdegradasi dan menyebakan korosi. Adapun konsentrasi oksidator ini dapat diprediksi dengan menggunakan simulasi program facsimile. Sehingga data laju dosis ini dapat dipergunakan selanjutnya untuk input parameter pada program facsimile untuk melihat produk-produk radiolisis akibat interkasi radisi dengan material dalam hal ini air.

\section{KESIMPULAN}

Berdasarkan data hasil percobaan didapatkan bahwa hubungan antara laju dosis radiasi terhadap sumber radiasi dalam hal ini bahan bakar bekas pada kolam ISSF dengan air sebagai medium penahan radiasi sinar gamma didapatakan hasil yaitu semakin besar jarak detektor terhadap sumber radiasi semakin kecil laju dosis yang terukur dan bersifat eksponensial hal ini sesuai dengan teori dimana laju dosis bersifat ekspnensial terhadap jarak dan sesuai dengan hukum kuadrat terbalik. 


\section{DAFTAR PUSTAKA}

1. Noor Cipta A. A. Studi deskriptif dosis radiasi pada pekerja di Interim Storage-1 Pusat Teknologi Limbah Radioaktif Badan Tenaga Nuklir Nasional tahun 2013-2014. Skripsi Fakultas Kedokteran dan Ilmu Kesehatan, UIN-Syarif Hidayatullah jakarta, 2015.

2. Kusumastuti R. dan Sunaryo G.R. Analisis laju korosi material ALMg2 dan SS304 dalam lingkungan air kolam penyimpanan bahan bakar bekas (ISSF). Prosiding seminar nasional teknologi pengelolaan limbah XII 2014, Pusat Teknologi Limbah Radioaktif.

3. Perbangkara H. Estimasi Dosis Radiasi pada Pemeriksaan CT Angiografi Coroner. Skripsi FMIPA-Fisika, Universitas Indonesia, Mei, 2011.

4. Silvia Sari. Pengembangan sistem manajemen keselamatan radiasi sinar-X di Unit Kerja Radiologi Rumah Sakit XYZ Tahun 2011, Skripsi Fakultas Kesehatan Masyarakat, Universitas Indonesia, 2012.

5. Ariyanto S. Perhitungan radiasi Alpa, Beta dan Gamma, Widyanuklida 1998, 1 (2).

6. Butarbutar S.L., Sriyono, Sunaryo G.R. Temperature dependence of primary species $\mathrm{G}$ (values) formed from radiolysis of water by interaction of tritium $\beta$ particles. Jurnal Pengembangan Energi Nuklir 2017; 19 (1): 17-23.

7. Nielsen F. and Jonsson M. Geometrical alpha- and beta-dose distributions and production rates of radiolysis products in water in contact with spent nuclear fuel. Journal of Nuclear Materials 2006; 359 (2); 1-7.

8. Nielsen F. and Jonsson M. Simulations of $\mathrm{H} 2 \mathrm{O} 2$ concentration profiles in the water surrounding spent nuclear fuel taking mixed radiation fields and bulk reactions into account._Journal of Nuclear
Materials 2008; 374 (2): 281-285.

9. Sunaryo G.R. The effect of boric on radiolysis product of hydrogen peroxide when Irradiated by gamma-ray, Journal of Water Chemistry of Nuclear Reactor Systems 2000: 271-274.

10. Raima, Stephen, et al. Radiolysis driven changes to oxide stability during irradiation corrosion of $316 \mathrm{~L}$ stainless steel in high temperature water, Journals of Nuclear Materials 2017; 493: 40-52.

11. Jonsson $\mathrm{M}$, et al .Radiation induced spent nuclear fuel dissolution under deep repository conditions. Journal of Environmental Science and Technology 2007; 41 (20): 7087-7093. 